\title{
Can A Commercially Oriented Brand Be Authentic? A Preliminary Study Of The Effects Of A Pro-Business Attitude On Consumer-Based Brand Authenticity
}

Stefano Pace, Kegde Business School, France

\begin{abstract}
The scholarly literature and general feeling support the idea that brands that are overly businessminded and commercially oriented are not authentic. Typically, consumers do not regard big corporations as authentic, due to the perception that corporations focus on making profit and their business-based mindset. In particular, consumers perceive commercially oriented brands are insincere. Sincerity is one of the three facets (quality commitment and heritage are the other two) that form consumer-based brand authenticity (Napoli, Dickinson, Beverland, \& Farrelly, 2014). Contrary to that long-held assumption, this study suggests that consumers may perceive commercially oriented brands are sincere. A positive attitude toward business may increase the perceived brand sincerity. The results of this empirical research confirm the brand authenticity scale developed by Napoli et al. (2014) by showing the conditions under which commercially oriented brands may enter the group of sincere brands.
\end{abstract}

Keywords: Authenticity; Brand; Attitude Toward Business; Consumer-Based Brand Authenticity; Marketing Consumer Behavior

\section{INTRODUCTION}

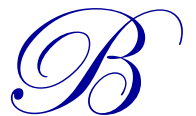

rand authenticity has received increasing interest in scholarly research and managerial practice (Gilmore \& Pine, 2007). Authentic brands have a "powerful mystique or aura" (Beverland, 2009, p. 37) through which they connect with their customers in a deeper way compared to conventional brands. Authenticity can ensure a company's long existence, as in the case of the small English auto-maker Morgan Motor Company, which celebrated its centenary during a crisis that threatened other car manufacturers (Beverland, 2009). The mark of authenticity is not reserved for a particular sector or type of brand. Big and small companies, service or product brands, young or old brands, can be perceived as authentic. However, a common trait of authentic brands is their unique position in the market. An authentic brand does not concede too much to the requests of business and maintains distance from a commercial mentality, even though business practices are necessary for any company. The "club" of authentic brands seems composed of a limited set of brands that remain true to noncommercial values.

This research suggests that consumers can perceive commercially oriented companies are sincere. In particular, consumers with a good attitude toward business in general do not consider the commercial nature of a brand inherently wrong and may perceive some sincerity in commercial brands. Sincerity is one component of consumer-based brand authenticity (Napoli, Dickinson, Beverland, \& Farrelly, 2014). Therefore, commercially oriented brands remain less authentic, but their sincerity may be recognized in the market.

The paper is organized as follows. The theoretical section offers a synthesis of key features of the literature on brand authenticity regarding commercial orientation. Then the section focuses on brand sincerity. The theoretical perspectives illustrated in this section suggest that consumers do not necessarily reject the sincerity of a 
commercially oriented brand. More specifically, consumer attitudes toward business in general affect the perceived sincerity of a brand. In the second section, a series of empirical studies aimed at providing preliminary support to the idea that commercially oriented brands can be perceived as sincere by consumers are described. The implications of the research are illustrated at the end of the paper.

\section{THEORETICAL BACKGROUND}

\section{Authenticity and Commercial Orientation}

Authenticity-due to its rich nature- has various definitions and may escape a commonly shared designation. However, recurring ideas that form authenticity are naturalness, sincerity, truthfulness, honesty, and the like. Truth, genuineness, and reality are the essential nature of authenticity (Beverland \& Farrelly, 2010).

Authenticity —in particular, its component of sincerity —is typically the opposite of the idea of business and commerciality. If a brand shows commercial motives, in the eyes of consumers the brand's authenticity is lost. For instance, luxury wine producers, to convey an authentic image, should express a public disavowal of commercial intents and marketing approaches (Beverland, 2005, 2006). In particular, being sincere means telling a brand story that appears "above commercial considerations" (Beverland, 2005, p. 1017). Even when a company adopts modern technologies, up-to-date managerial practices, and marketing techniques, the company's authentic image is conveyed through traditionally handcrafted processes that deny a commercial orientation.

As observed by Holt (2002), in postmodern marketing, to

"be authentic, brands must be disinterested; they must be perceived as invented and disseminated by parties without an instrumental economic agenda, by people who are intrinsically motivated by their inherent value. Postmodern consumers perceive modern branding efforts to be inauthentic because they ooze with the commercial intent of their sponsors" (p. 83).

Consumers use brands as marketplace resources that connect with the consumers' inner and authentic selves (Arnould \& Price, 2000). In this cultural and personal operation, only sincere brands can be of use, because commercial intentions do not taint the brands.

Mass-marketed objects are often perceived as inherently untrue, because they serve the commercial aims of the manufacturer, rather than pursuing higher and more universal values. In addition, products comply with economies of scale and thus are replicated to reach wide markets, while the authentic object is a unique piece that is almost artistic (Leigh, Peters, \& Shelton, 2006). In the process of creating the authenticity of products, subjects search for indexical or iconic cues (Grayson \& Martinec, 2004) that would confirm the idea of something placed out of the market, preferably in an utopian past that suggests a long heritage (Brown, Kozinets, \& Sherry, 2003). What is outside the mainstream market is more authentic. Consumers themselves can create spaces (autonomous from market offers) where they substitute common commercial myths with more authentic ones (Kozinets, 2002) or create a pre-market environment where they re-enact and live myths of the past, when markets were not an overwhelming trait of society (Belk \& Costa, 1998).

Despite the idea that market and authenticity are opposite notions, some studies suggest that consumers can perceive commercially oriented brand as authentic, too. Kates (2004) argues that - in contrast to the common contention that mass-marketed brands cannot be authentic - "the authentic may be potentially located in select massmarketed brands" (p. 463). Subcultures of consumption engage in processes of legitimization through which, within a given subculture, consumers appreciate a brand as authentic. Any brand, as far as it respects or advocates the concerns of the subculture of consumption, can be authentic. When customers believe a brand is morally legitimate within their subculture, they reward the company by becoming loyal customers (Kates, 2004). Therefore, consumers do not deny a commercial relation with an authentic brand but use that commercial relation as a form of appreciation of the brand's cultural position within the subculture. For instance, in the study by Kates (2004) on gay subculture, when one informant discovered that a brand of tuna was gay-friendly (because it advertised in a local gay-friendly 
newspaper), he promised to become a loyal patron of that brand. Consumers recognize that the commercial aims of a brand do not necessarily contradict the aim of pursuing higher social issues that are of concern for the subculture.

One way a brand can build sincerity and remain distant from commercialism is to connect with communities and subcultures (Holt, 2002). When a community or a subculture adopts a brand as a cultural symbol (Muñiz \& O'Guinn, 2001; Schouten \& McAlexander, 1995), the brand gains an aura of sincerity, because the brand's cultural aspects and linking values (Cova, 1997) are emphasized. This community-based banner of sincerity sets the brand apart from other more commercial brands. In a more advanced authentication of brands, current communities express an entrepreneurial spirit by forming their own marketplaces and interacting with the commercial aspects of their preferred brand (Cova, Kozinets, \& Shankar, 2007). A brand community does not limit its elaboration of the brand to mere worship. A brand community can customize and trade brands (Schau, Muñiz, \& Arnould, 2009). Through this commoditization, the commercial aspect of a brand is not discarded, but instead reaffirmed as one of the bases of the brand's authenticity. Consumer collectives confirm that the commercial aspects of the brand do not necessarily contradict its sincerity.

Beverland and Farrelly (2010) confirm that mass-marketed brands can be authentic. Some unusual suspects enter the realm of possibly authentic brands. For instance, McDonald's is sometimes fiercely criticized for its pervasive presence, which makes this brand a symbol of feared commercial globalization. Yet consumers can adopt that same wide diffusion of McDonald's fast-food restaurants as proof that McDonald's is democratically available to anyone and thus is authentic. The widespread diffusion of McDonald's fast-food restaurants creates a connection among people, a goal consumers pursue in their quest for authenticity (Beverland \& Farrelly, 2010). The voice of a consumer interviewed by Beverland and Farrelly (2010) vividly shows the easy access of this brand as a connective and authentic aspect: "[McDonald's is] just there, in your face, everywhere. It's just something that everyone indulges in without, you know, worrying. McDonald's is just there, it's just there to be enjoyed all the time" (p. 850).

Authenticity is in fact a creation of the individual (Beverland \& Farrelly, 2010) or collective consumer (Kates, 2004; Leigh et al., 2006), rather than an inherent trait of the brand. Consumers adopt strategies to imbue brands with authenticity, as an act of referencing to their true self (Beverland \& Farrelly, 2010). Therefore, no brand can be aprioristically judged inauthentic, and highly commercial brands can be authentic, too. Consumers apply a strategy of reduction, which consists of "eliminating superfluous elements to find the essence of a brand" (Beverland \& Farrelly, 2010, p. 852) so they can find the brand's true core. An individual can overlook the excessive commercial orientation of a brand and focus on its more authentic facets. Thus consumers maintain the brand's overall authenticity.

Instead of being the opposite of the artisanal unique pieces, and thus inauthentic, mass-marketed brands are often cited by consumers as typical authentic brands. These brands are mainstream representations of shared cultures, evolve with them, and therefore allow consumers to connect with the larger society in which they live (Beverland \& Farrelly, 2010) and to engage in a self-authenticating act.

Considering an overly commercial brand authentic may sound paradoxical. Actually, a paradox is a recurring feature of authenticity and part of its complexity. The complex co-creative role of the consumer explains this paradox. Consumers co-create authenticity. Visitors to an explicitly fictional place such as the house of the fictional character Sherlock Holmes create a complete sense of authenticity. Consumers combine unverifiable iconic cues and concrete indexical cues to create an authentic experience (Grayson \& Martinec, 2004). Similarly, spectators of television reality shows - an example of phoniness and artificiality - can extract authenticity from fantasy (Rose \& Wood, 2005).

We can inscribe the commercial-yet-sincere brands in the "post postmodern" phase envisaged by Holt (2002) in consumer culture. The inflation of authentic brand narratives creates contradictions in authenticity. That leads to a situation in which "[b]rands will no longer be able to hide their commercial motivations. When all brands are understood as commercial entities, through and through, consumers will be less inclined to judge a brand's authenticity by its distance from the profit motive" (Holt, 2002, p. 87). Therefore, consumers can consider the 
commercial intent of a brand a normal trait. Unless this commercial orientation overpowers all other brand values, consumers may approve of the brand and preserve its authenticity by acknowledging the brand's sincerity.

If consumers - by applying authenticating strategies - can satisfy their goals of control, connection, or moral virtue through a brand (Beverland \& Farrelly, 2010), then a brand is authentic. In summary, consumers can attribute authenticity to any brand, including commercially oriented brands.

\section{Brand Sincerity}

Recently, Napoli et al. (2014) developed a consumer-based brand authenticity (CBBA) scale. The scale measures brand authenticity; thus, scholars can understand this construct, and practitioners can adopt a managerial tool for their market decisions. The scale is made up of three dimensions: quality commitment, heritage, and sincerity. Sincerity captures the value and principles of the brand. Brand sincerity is the dimension through which a consumer validates whether the brand is loyal to its core tenets. Thus, through brand sincerity a consumer assesses whether those tenets include a commercial orientation.

The CBBA scale measures brand sincerity with two items: "The brand refuses to compromise the values upon which it was founded" and "The brand has stuck to its principles" (Napoli et al., 2014). Similar to the concept of authenticity that emerged from the previous discussion, the two items do not mention the types of values, but instead the tie between the brand and those values. In abstract terms, the consumer can consider any values an expression of sincerity, as long as the brand maintains its connection with those values. Naturally, given the morality of authentic brands, one can expect that clearly unethical values (such as spoiling the natural environment or exploiting consumers) expunge sincerity from a brand.

Concerning the two items of brand sincerity, the authors notice that "[i]nterestingly, specific items related to consumers' perceptions of a brand's commercial motives did not emerge during analysis" (Napoli et al., 2014, p. 1095). The authors could have expected the presence of non-commercial or even anti-commercial elements in the emerging items. In contrast, consumers do not assign a specific sense of inauthenticity to brands that are commercially oriented. The lack of mention of the commercial aspect in the brand sincerity dimension should not surprise, given the theoretical observations. If a commercially oriented brand can be as authentic as any other brand, consumers would not check the commerciality of a brand to assess its authenticity. As for sincerity, consumers might exclude unethical brands from the realm of authenticity and then assess how much the brand is rooted in its principles, including commercial values if they are the brand's core values.

In the following studies, we investigate whether consumers can perceive a commercially oriented brand is sincere.

\section{STUDY SET A: DOES CULTURAL CONTEXT AFFECT PERCEIVED BRAND SINCERITY?}

\section{Overview}

The aim of the first set of studies was to explore the differences between cultures in terms of brand sincerity. The first study showed whether differences exist in how two different cultures perceive the sincerity of a commercially oriented brand. We expected that no difference would emerge, because consumers' perception of authenticity would occur at the individual level.

We compared two samples of consumers drawn from two distinct cultural contexts: the United States and Canada. U.S. and Canadian cultures have common values. However, some cultural values still differentiate the two countries. The Environics Institute for Survey Research has led one of the longest and most complete longitudinal studies about the cultural differences of these two countries (Adams, 2004). Canadian culture is characterized by a more intense idealism and openness to "up-to-date" values. On average, Canadians are suspicious about money and advocate income redistribution. In contrast, the American culture adopts a competitive "winner takes all" approach, and ingenuity in any domain - including business - is highly valued (Adams, 2014). U.S. culture has a more positive attitude toward business. If a cultural effect is at work, we expected that U.S. consumers would evaluate 
commercially oriented brands as more sincere. However, given the observations on individual self-authenticating acts, this cultural effect should not emerge, and thus, we expected that U.S. and Canadian consumers would not differ in their perception of brand sincerity.

\section{Study A1: Extracting a Commercially Oriented Brand}

\section{Method}

The aim of the first data collection was to get a brand that is perceived as commercially oriented by U.S. and Canadian consumers. A brand drawn from this data collection was used in the next study A2, which measured the sincerity of the brand as perceived in the two countries. Data were collected with an online survey. The research was conducted through an online service that presents pop-up items to a wide population of Internet users while they browse the Web. Two distinct data collections were executed: one for U.S. and one for Canadian individuals. Both groups were presented with the same open-ended question: "Indicate a brand that is motivated solely by business considerations and excessive commercial orientation."

Results

The pop-up item with the open-ended question was delivered through 828 impressions for U.S. users and 715 impressions for Canadian users. The response rates were $15.8 \%$ and $18.6 \%$, respectively, for a total of 131 U.S. and 133 Canadian respondents. The socio-demographic features of the two samples - as deduced by the service providers - show that the samples were a good representation of the general populations.

Table 1 lists the first three brands that the two samples cited as commercially oriented.

Table 1. Three Brands Most Frequently Cited As Commercially Oriented: Comparison Of U.S. And Canadian Respondents

\begin{tabular}{cc|cc}
\hline \multicolumn{2}{c|}{$\begin{array}{c}\text { U.S.A. } \\
(\mathbf{N = 1 3 1})\end{array}$} & \multicolumn{2}{c}{$\begin{array}{c}\text { Canada } \\
(\mathbf{N}=\mathbf{1 3 3})\end{array}$} \\
\hline Nike & $7.6 \%$ & Apple & $9.8 \%$ \\
Apple & $5.3 \%$ & Nike & $7.5 \%$ \\
Comcast & $5.3 \%$ & Coca-Cola & $5.3 \%$ \\
\hline
\end{tabular}

In both groups, Apple and Nike were cited more frequently as motivated solely by business considerations and excessive commercial orientation. The respondents also mentioned various other brands, with less frequency. The majority of the brands in both samples are big corporations. Many of the commercially oriented brands indicated by the respondents are global brands. These details agree with the idea that consumers perceive big multinational corporations as commercially oriented entities. Apple seems to have moved from its past positioning as an authentic brand distinct from the mainstream to a more commercially perceived positioning. This move toward a less authentic perception is likely due to the changes that occurred at the top management of Apple after the demise of its mythical co-founder Steve Jobs, who was one of the key sources of Apple authenticity (Beverland, 2009). A consistent and aesthetically appealing design has always been a signature of the Apple brand. A perceived change in design might cause negative reactions by some consumers who are more loyal to the previous era of Apple, when Steve Jobs was at the helm of the company, and ensuring his stylistic signature. The negative reaction by consumers would impinge on the authenticity of the brand, because stylistic consistency and a design that evolves with the times are key elements of brand authenticity (Beverland, 2006; Napoli et al., 2014). However, the aim of this data collection was not to get a definitive list of the most commercially oriented brands. The aim was to define a brand to submit to two new samples of users from the two countries (see the next study) and compare the perceived sincerity of that brand. 


\section{Study A2: Comparing Brand Sincerity in U.S. and Canadian Consumers}

\section{Method}

In this study, we took a brand from the previous survey and compared U.S. and Canadian consumers' perception of the brand's sincerity. By considering a common brand across the two samples, we could control for any effect due to specific brand features. For instance, selecting Comcast for the U.S. sample and Apple for the Canadian sample would not lead to reliable results, since we were not interested in the level of sincerity of the two brands, but in a comparison between the two groups of respondents. The brand for this study was Apple. For the data collection, the same technique used in the previous data collection was adopted. To measure the sincerity of the Apple brand, we used two items developed by Napoli and colleagues (2014), and inserted the name Apple in their wording, as follows: "The brand Apple refuses to compromise the values upon which it was founded" and "The brand Apple has stuck to its principles." Each item was measured with a seven-point scale, anchored at "I completely disagree" and "I completely agree"; a score of 7 indicated the maximum perceived sincerity. For each of the two items that measured the brand's sincerity (Napoli et al., 2014), we collected data from distinct U.S. and Canadian samples (see Table 2). In total, four samples of about 130 respondents each were used as follows: one U.S. and one Canadian sample for the first brand sincerity item and one U.S. and one Canadian sample for the second item.

We expected that the U.S. and Canadian consumers would not differ in terms of perceived brand sincerity.

\section{Results}

Table 2 shows the scores for brand sincerity in the two samples. As expected, no significant differences emerged between U.S. and Canadian consumers.

Table 2. Sincerity of the brand Apple in the U.S. and Canadian samples

\begin{tabular}{lccc|ccc|cc}
\hline & \multicolumn{3}{c|}{ U.S.A. } & \multicolumn{3}{c|}{ Canada } & \multicolumn{2}{c}{ Difference } \\
\cline { 2 - 9 } & $\mathrm{N}$ & Mean & St. Dev. & $\mathrm{N}$ & Mean & St. Dev. & $\begin{array}{c}\mathrm{t}_{\text {(df) }} \\
\text { (two value tailed) }\end{array}$ \\
\hline $\begin{array}{l}\text { The brand Apple refuses to } \\
\text { compromise the values upon which } \\
\text { it was founded }\end{array}$ & 139 & 3.87 & 2.03 & 131 & 4.12 & 1.89 & $1.046_{(268)}$ & .297 \\
$\begin{array}{l}\text { The brand Apple has stuck to its } \\
\text { principles }\end{array}$ & 133 & 4.35 & 1.97 & 130 & 4.04 & 1.77 & $1.341_{(261)}$ & .180 \\
\hline
\end{tabular}

This first set of studies suggested that the individual elaborates her or his perception of brand sincerity. The surrounding cultural context (which can be more or less commercially oriented and business friendly) can influence this evaluation, but it is not so strong to determine a difference at the cultural level. Although the cultural context can be business friendly or unfriendly, the final perception of brand sincerity remains an individual attitude.

\section{Study B: Effects of Attitude toward Business on Customer-Based Brand Sincerity}

\section{Overview}

This study assessed the main argument of this research, which is the effect of the attitude toward business on customer-based brand sincerity. An online survey was administered to an international sample of respondents. Given the results of study A, we expected that the cultural contexts would not exert a strong influence of the perceived brand sincerity. Thus, the sincerity scale score is a valid measure of a consumer's individual evaluation of brand sincerity. Respondents were asked to rate the sincerity of the Apple brand. Apple was selected for consistency with the results of the previous study and because Apple is a global brand known at an international level. The respondents' attitude toward business was measured to examine its relation with the perceived brand sincerity. Brand familiarity and socio-demographic questions were also part of the questionnaire. To minimize method bias 
across studies A and B, the online questionnaire was administered through different online platforms. In study B, the questionnaire was administered through an international crowd-working platform.

Method, Measures, and Sample

Attitude toward business was measured with a three-item scale drawn from a six-item scale used in the literature (Muncy \& Vitell, 1992; Patwardhan, Keith, \& Vitell, 2012; Richins, 1983; Vitell \& Muncy, 2005). Of the original six-item scale, we omitted the three reverse-coded items, because that type of item might create confusion in the respondents and some scholars advise avoiding the items since the disadvantages of reverse-coding obfuscate any benefits (DeVellis, 2003). The measure used a five-point Likert scale ranging from 1 (strongly disagree) to 5 (strongly agree). The two items for sincerity were those developed by Napoli et al. (2014, p. 1093): "The brand refuses to compromise the values upon which it was founded" and "The brand has stuck to its principles." The brand Apple was explicitly mentioned in the wording of the scale. To ascertain that the respondents knew the brand, brand familiarity was measured with a variation of Zhou, Yang, and Hui's (2010) three-item scale. Zhou et al.'s (2010) scale adopted a semantic differential format. To ensure consistency with the other scales used in the study, each semantic differential was transformed into a Likert scale. The appendix shows the scales that were used.

The sample was composed of 150 respondents. The countries of origin varied, and encompassed different continents: Europe (58\%), the Americas (30\%), Asia (10\%), and Africa (2\%). The English proficiency of the respondents was confirmed by the crowd-working platform. To double-check, the respondents' language expertise was also assessed through a self-evaluation of their English proficiency, which showed an average score of 4.3 on a $1-5$ scale $(81 \%$ of respondents scored 4 or 5). Male respondents were $71 \%$ of the sample. The average age was 32 years $(\mathrm{SD}=9.96)$, with a minimum age of 18 and a maximum of 69 years. Most respondents were single or never married (61\%), followed by married or engaged in a domestic partnership (34\%). Bachelor and master degrees were the most common educational levels $(47 \%)$.

Results

To ensure that the respondents had viable familiarity with the Apple brand, questionnaires that showed a degree of familiarity with the brand (Zhou et al., 2010) lower than 3 (on a 1-5 scale) were excluded. Consumers with a low level of familiarity with the brand would not have a reliable perception of the brand features or a stable attitude. Through this filtering, 26 questionnaires were excluded, and the final sample consisted of 124 questionnaires. Table 3 shows statistics of the three scales (consumer-based brand sincerity, attitude toward business, and brand familiarity in its two versions). For brand familiarity, the original scale showed low convergent validity, with a Cronbach alpha of. 48. This may be because one item of the scale refers to knowledge of the brand's advertising. Apple likely has different advertising pressures in different countries, with varied knowledge of its ads. After the item was removed, the scale reached satisfying reliability (see the variable labeled "Brand familiarity (no ads)" in Table 3).

Table 3. Statistics (Mean, SD, Scale Reliability, And Correlations) Of The Scales In The Final Sample (N=124)

\begin{tabular}{|c|c|c|c|c|c|c|}
\hline & Mean & SD & $\begin{array}{l}\text { Cronbach alpha (on } \\
\text { standardized values) }\end{array}$ & $\begin{array}{c}\text { Attitude toward } \\
\text { business }\end{array}$ & $\begin{array}{c}\text { Brand } \\
\text { familiarity }\end{array}$ & $\begin{array}{c}\text { Brand familiarity } \\
\text { (no ads) }\end{array}$ \\
\hline Brand sincerity & 3.38 & .89 & .66 & $0.341 * *$ & $0.217^{*}$ & .166 \\
\hline Attitude toward business & 3.70 & .66 & .81 & & $0.280 *$ & $.294 * *$ \\
\hline Brand familiarity ${ }^{a}$ & 4.04 & .65 & .48 & & & $.883^{* *}$ \\
\hline Brand familiarity (no ads) & 3.99 & .82 & .72 & & & \\
\hline
\end{tabular}

To analyze the data, we used regression analysis with brand sincerity as a dependent variable, attitude towards business as an independent variable, and brand familiarity as a control variable (together with age). Different regression models are compared in Table 4. 
Table 4. Regression models

\begin{tabular}{|c|c|c|c|c|c|c|c|c|}
\hline & & & & $\begin{array}{r}\text { Non-sta } \\
\text { Coef }\end{array}$ & $\begin{array}{l}\text { rdized } \\
\text { nts }\end{array}$ & $\begin{array}{l}\text { Standardized } \\
\text { Coefficients }\end{array}$ & & \\
\hline Model & $\mathrm{R}^{2}$ & Adjusted $\mathrm{R}^{2}$ & & $\beta$ & S.D. & $\beta$ & $\mathbf{t}$ & Sig. \\
\hline \multirow{2}{*}{1} & \multirow{2}{*}{.116} & \multirow{2}{*}{.101} & Constant & $1.692 * *$ & .429 & & 3.941 & .000 \\
\hline & & & Attitude toward Business & $.457 * *$ & .114 & .341 & 4.002 & .000 \\
\hline \multirow{3}{*}{2} & \multirow{3}{*}{.132} & \multirow{3}{*}{.111} & Constant & $1.684 * *$ & .511 & & 3.298 & .001 \\
\hline & & & Attitude toward Business & $.457 * *$ & .115 & .341 & 3.983 & .000 \\
\hline & & & Age & .000 & .008 & .002 & .028 & .978 \\
\hline \multirow{4}{*}{3} & \multirow{4}{*}{.121} & \multirow{4}{*}{.099} & Constant & 1.448 & .588 & & 2.463 & .015 \\
\hline & & & Attitude toward Business & $.429 * *$ & .120 & .320 & 3.570 & .001 \\
\hline & & & Age & .001 & .008 & .010 & .119 & .905 \\
\hline & & & Brand Familiarity & .080 & .098 & .073 & .814 & .418 \\
\hline
\end{tabular}

In each model, attitude toward business had a positive significant effect on the perception of brand sincerity; that is, the higher the attitude toward business, the higher the perceived brand sincerity. Age and brand familiarity did not affect brand sincerity.

\section{DISCUSSION AND CONCLUSIONS}

The results suggest that commercially oriented brands can be perceived as sincere as long as consumers hold a positive attitude toward business. A positive attitude toward business has an effect on the perceived brand sincerity, and increases consumer-based brand sincerity. Among the values of a brand, commercial intent is listed as a possible value and is not detrimental to brand sincerity. Naturally, the overarching characteristic of the brand should be its morality and its ethical values, which should represent a compass for any business decision. A company should not pursue commercial aims without having a clear ethical approach to the market. This approach is an essential feature of an authentic brand (Beverland, 2006; Beverland \& Farrelly, 2010) and affects its sincerity.

Consumers today are free bricoleur of marketplace resources (Arnould \& Thomson, 2005), including brands, and they seek authenticity. Consumers can distinguish the various facets that form the cultural positioning of a brand. They can accept the business-based mindset of a brand as part of its identity. Some current theoretical frameworks support the idea that a brand has anthropomorphic features and consumers relate to the brands as such. However, differently from the human self, a brand has an inherent commercial facet, as small and unimportant as it may be compared to other aspects. Consumers with a positive attitude toward business acknowledge this commercial side, which is peculiar to brands, and include it in their perception of brand sincerity. Our results are in line with the theoretical reasoning that would expect a consumer who can negotiate marketplace resources in a complex way. Consumers may refuse a too strong boundary dividing commercial insincere brands from sincere acommercial brands. Individuals would rather work with this boundary and accept the sincerity of commercial brands. Attitude toward business is a pivotal mechanism for this perception of sincerity.

Among the implications for managers, brand managers should not necessarily downplay market-based reasoning in their brand positioning when they address consumers with a positive attitude toward business. In particular, economic crises may make a firm's performance a salient element in consumers' attitude toward brands. Individuals, during periods of crises, react more to corporations' actions, which would negatively affect the attitude toward business in general. Economic crises call for a renewed effort by brands to show how they contribute to the economic well-being of the societies in which the companies operate. By emphasizing a positive economic impact, a brand manager can counter-act consumers' negative attitude toward the business during crises and increase the sincerity emanating from the brand. Another managerial implication refers to the economic and financial communications that brands should issue. Managers usually believe these communications are beyond the scope of marketing communication and are reserved for investors. In contrast, financial and economic statements are part of marketing communications. Consumers with a positive attitude toward the business can transfer a positive impression regarding a positive performance to their perceived sincerity of the brand. The present study is in the direction of the call by Napoli et al. (2014) for further research on brand sincerity: "sincerity may be a more complex construct that involves a wider range of issues beyond those identified here. [...] [A]dditional research 
could shed more light" (p. 1095). Further research will increase understanding of consumer-based brand sincerity. A promising direction for future research is toward other consumer attitudes and traits. For instance, materialism can affect the perception of brand sincerity. Future studies can further advance our knowledge on the multifaceted interaction between economic and cultural sides of brands.

Future studies can overcome the limitations of this preliminary work, including studies on different brands, the extension of the research on the other dimensions of the brand authenticity, and an enrichment of the factors involved in the consumers' perception of brand authenticity.

\section{AUTHOR INFORMATION}

Stefano Pace, PhD, is Associate Professor in consumer behavior and marketing at Kedge Business School (Marseille, France). He received his $\mathrm{PhD}$ in Business Administration \& Management from Bocconi University (Milan, Italy) where he has been the Director of the Master in Marketing \& Communication and currently teaches courses on consumer behavior. He is a member of the editorial board of Industrial Marketing Management and Journal of Innovation Management. His publications include articles in international peer-reviewed journals such as Organization, Journal of Business Ethics, Marketing Theory, Marketing Letters, International Marketing Review, European Journal of Marketing, Group Decision, and Negotiation. E-mail: stefano.pace@kedgebs.com

\section{REFERENCES}

Adams, M. (2004). Fire and ice revisited: The United States, Canada and the myth of converging values. Toronto, Canada: Penguin Canada.

Arnould, E. J., \& Price, L. L. (2000). Authenticating acts and authoritative performances: Questing for self and community. In S. Ratneshwar, D. G. Mick, \& C. Huffman (Eds.), The why of consumption:

Contemporary perspectives on consumer motives, goals, and desires (pp. 140-163). London, England: Routledge.

Arnould, E. J., \& Thompson, C. J. (2005). Consumer culture theory (CCT): Twenty years of research. Journal of Consumer Research, 31(March), 868-882.

Belk, R. W., \& Costa, J. A. (1998). The mountain man myth: A contemporary consuming fantasy. Journal of Consumer Research, 25(December), 218-240.

Beverland, M. B. (2005). Crafting brand authenticity: The case of luxury wine. Journal of Management Studies, 42(5), 1003-1029.

Beverland, M. B. (2006). The "real thing": Branding authenticity in the luxury wine trade. Journal of Business Research, 59(2), 251-258.

Beverland, M. B. (2009). Building brand authenticity: 7 habits of iconic brands. Basingstoke, England: Palgrave Macmillan.

Beverland, M. B., \& Farrelly, F. J. (2010). The quest for authenticity in consumption: Consumers' purposive choice of authentic cues to shape experienced outcomes. Journal of Consumer Research, 36, 833-856.

Brown, S., Kozinets, R. V., \& Sherry, J. F. (2003). Teaching old brands new tricks: Retro branding and the revival of brand meaning. Journal of Marketing, 67(3), 19-33.

Cova, B. (1997). Community and consumption: Towards a definition of the "linking value" of product or services. European Journal of Marketing, 31, 297-316.

Cova, B., Kozinets, R. V., \& Shankar, A. (2007). Consumer tribes. Oxford, England: Elsevier.

DeVellis, R. F. (2003), Scale development: Theory and applications. Thousand Oaks, CA: Sage.

Grayson, K., \& Martinec, R. (2004). Consumer perceptions of iconicity and indexicality and their influence on assessments of authentic market offerings. Journal of Consumer Research, 31(September), 296-312.

Holt, D. B. (2002). Why do brands cause trouble? A dialectical theory of consumer culture and branding. Journal of Consumer Research, 29(June), 70-90. 
Kates, S. M. (2004). The dynamics of brand legitimacy: An interpretive study in the gay men's community. Journal of Consumer Research, 31(September), 455-464.

Kozinets, R. V. (2002). Can consumers escape the market? Emancipatory illuminations from Burning Man. Journal of Consumer Research, 29(June), 20-38.

Leigh, T. W., Peters, C., \& Shelton, J. (2006). The consumer quest for authenticity: The multiplicity of meanings within the MG subculture of consumption. Journal of the Academy of Marketing Science, 34(4), 481-493.

Muncy, J. A., \& Vitell, S. J. (1992). Consumer ethics: An investigation of the ethical beliefs of the final consumer. Journal of Business Research, 24(4), 297-311.

Muñiz, A., \& O'Guinn, T. C. (2001). Brand communities. Journal of Consumer Research, 27(March), 412-432.

Napoli, J., Dickinson, S. J., Beverland, M. B., \& Farrelly, F. (2014). Measuring consumer-based brand authenticity. Journal of Business Research, 67(6), 1090-1098.

Patwardhan, A. M., Keith, M. E., \& Vitell, S. J. (2012). Religiosity, attitude toward business, and ethical beliefs: Hispanic consumers in the United States. Journal of Business Ethics 110(1), 61-70.

Gilmore, J. H., \& Pine, B. J., II (2007). Authenticity: What consumers really want. Boston, MA: Harvard Business School Press.

Richins, M. L. (1983). An analysis of consumer interaction styles in the marketplace. Journal of Consumer Research, 10(June), 73-82.

Rose, R. L., \& Wood, S. L. (2005). Paradox and the consumption of authenticity through reality television. Journal of Consumer Research, 32(September), 284-296.

Schau, H. J., Muñiz, A. M., Jr., \& Arnould, E. J. (2009). How brand community practices create value. Journal of Marketing, 73(September), 30-51.

Schouten, J. H., \& McAlexander, J. A. (1995). Subcultures of consumption: An ethnography of the new bikers. Journal of Consumer Research, 22(June), 43-61.

Vitell, S. J., \& Muncy, J. (2005). The Muncy-Vitell consumer ethics scale: A modification and application. Journal of Business Ethics, 62, 267-275.

Zhou, L., Yang, Z., \& Hui, M. K. (2010). Non-local or local brands? A multi-level investigation into confidence in brand origin identification and its strategic implications. Journal of Academy of Marketing Science, 38(2), 202-218. 


\section{APPENDIX}

\section{Scales used in study B}

Attitude toward business (adapted from Muncy \& Vitell, 1992; Richins, 1983; Vitell \& Muncy, 2005)

- $\quad$ Most companies are concerned about their customers.

- $\quad$ In general, I am satisfied with most of the products I buy.

- $\quad$ The business community has helped raise our country's standard of living.

Brand sincerity (adapted from Napoli et al., 2014)

- $\quad$ The brand Apple refuses to compromise the values upon which it was founded.

- $\quad$ The brand Apple has stuck to its principles.

Brand familiarity (adapted from Zhou et al., 2010)

- $\quad$ The brand Apple is very familiar to me.

- $\quad$ I am very knowledgeable about the brand Apple.

- $\quad$ I have seen many advertisements about the brand Apple in the mass media. ${ }^{\mathrm{a}}$

${ }^{a}$ This item was removed from the analysis. 
NOTES 